\title{
The Major Histocompatibility Complex Class III Haplotype Ltab-Ncr3 Regulates Adjuvant-Induced but Not Antigen-Induced Autoimmunity
}

\author{
Anthony C.Y. Yau, Jonatan Tuncel, and Rikard Holmdahl
}

From the Division of Medical Inflammation Research, Department of Medical Biochemistry and Biophysics, Karolinska Institutet, Stockholm, Sweden

\author{
Accepted for publication \\ December 27, 2016. \\ Address correspondence to \\ Rikard Holmdahl, M.D., \\ Ph.D., Division of Medical \\ Inflammation Research, \\ Department of Medical \\ Biochemistry and Biophysics, \\ Karolinska Institutet, 17177 \\ Stockholm, Sweden. E-mail: \\ rikard.holmdahl@ki.se.
}

\begin{abstract}
Rheumatoid arthritis is a complex disease associated with $>100$ risk loci, with the strongest association from the major histocompatibility complex $(\mathrm{MHC})$ region. Here, we analyzed a new genetic association in the MHC class-III region (MHC-III) using adjuvant- and antigen-induced arthritis models. In addition, we used models for multiple sclerosis for comparison and dissected the MHC-III-mediated mechanisms of importance for antibody and T-cell responses to antigens. With the use of a panel of MHC-III recombinant inbred strains, we found that the 33-kb Ltab-Ncr3 haplotype in MHC-III was linked to the induction of arthritis with incomplete Freund's adjuvant, with similar effects in arthritis induced by several oil adjuvants (hexadecane, heptadecane, squalene, arlacel). Adoptive T-cell transfer experiment showed that this arthritis-protective effect operated during the priming of T cells by controlling their arthritogenicity. Interestingly, Ltab-Ncr3 did not regulate autoimmune diseases induced with tissue-specific antigens emulsified in adjuvant oils, such as collagen-induced arthritis or experimental autoimmune encephalomyelitis. No effect on antibody or T-cell response to tissue antigens in the LtabNcr3 could be demonstrated. The finding that Ltab-Ncr3 is specific in regulating adjuvant-induced arthritis but not antigen-induced autoimmunity, and with unique effects on priming of autoreactive and arthritogenic $T$ cells, provides new insight for understanding the regulation of autoimmune diseases. (Am J Pathol 2017, 187: 987-998; http://dx.doi.org/10.1016/j.ajpath.2016.12.022)
\end{abstract}

Rheumatoid arthritis (RA) is a chronic autoimmune joint disorder affecting $0.5 \%$ to $1 \%$ of the general population. RA is a polygenic disease with $>100$ RA risk loci identified in genome-wide association studies. ${ }^{1}$ The genetic association of RA is mainly from major histocompatibility complex (MHC) genes with minor contributions from non-MHC genes. The association between RA and MHC has been known for decades, ${ }^{2,3}$ and it was recently suggested that six amino acids in human leukocyte antigen (HLA)-DRB1, HLA-A, HLA-B, and HLA-DPB1 explain most of the MHC association with RA in seropositive patients. ${ }^{4,5}$ Genetic contributions from other regions within the $\mathrm{MHC}$, such as MHC class III (MHC-III), to RA have also been reported in several case-control studies. ${ }^{6,7}$

The association to MHC class II (MHC-II) has been shown in several animal models of RA. With the use of a panel of MHC-recombinant strains with different MHC-II haplotypes, we previously showed that $R T 1-B$ (the rat orthologs of $H L A-D Q$ ) determines the onset and severity of pristane-induced arthritis (PIA). ${ }^{8}$ In addition to $R T 1-B$, a second arthritis-regulatory quantitative trait locus (QTL) was recently found in the telomeric end of MHC-III. ${ }^{9}$ This latter QTL was mapped to a 33-kb interval (named Ltab$N c r 3$ ) comprising five genes, lymphotoxin $\alpha$ (Lta), tumour

\footnotetext{
Supported by King Gustav V 80th Birthday Foundation (R.H.), Knut and Alice Wallenberg Foundation grant KAW2010.0148 (R.H.), the Swedish Association against Rheumatism (R.H.), the Swedish Medical Research Council grant 521-2010-2894 (R.H.), the Swedish Foundation for Strategic Research (R.H.), the European Community's Seventh Framework Program under the grant agreements HEALTH-F4-2010-241504 (EURATRANS) (R.H.) and LSHG-Ct-2005-019015 (EURATools) (R.H.), and from the European Union Innovative Medicine Initiative (EU IMI) project BeTheCure (R.H.).

Disclosures: None declared.
} 
necrosis factor (Tnfa), lymphotoxin $\beta(L t b)$, leukocytespecific transcript 1 (Lstl), and natural cytotoxicitytriggering receptor $3(\mathrm{Ncr} 3)$. We showed that Ltab-Ncr3 regulates not only the onset and severity but also chronicity of PIA. ${ }^{9}$

In addition to PIA, there are other rat arthritis models reflecting different aspects of arthritis in humans, including cartilage-restricted type II collagen-induced arthritis (CIA) and mineral oil (ie, incomplete Freund's adjuvant, IFA)induced arthritis (OIA). CIA is induced by an injection of collagen type II (CII) emulsified in IFA. In contrast, PIA and OIA are induced by pure adjuvants, pristane and IFA, respectively; thus, the induction of arthritis in these models is independent of exogenous antigens. PIA and OIA are largely similar; both are driven by polyclonal $\mathrm{T}$ cells and can be transferred by T cells. ${ }^{10-12}$ The main difference between PIA and OIA is that pristane induces a chronic, relapsing disease course, whereas OIA is associated with an acute and relatively mild arthritis. ${ }^{13}$ CIA is more complex; in addition to sharing the T-cell dependence with PIA and OIA, it has the additional influence of B cells because of the in vivo affinity of CIIspecific antibodies for cartilage. ${ }^{14}$ All these arthritis models have been used to identify arthritis-regulatory QTLs, ${ }^{15-20}$ and different QTLs were shown to regulate different arthritis phenotypes. For instance, Pia2 and Pia3 regulate arthritis onset, Pia4 regulates arthritis severity, and Pia5 and Pia6 regulate chronicity of PIA. ${ }^{20}$ Most QTLs were associated with multiple arthritis models, usually both PIA and CIA. ${ }^{15,21}$ Some loci were only associated with certain arthritis models; for instance, Cia4 regulates PIA and OIA but not CIA, and Cia6 regulates OIA but not PIA and CIA, ${ }^{17-19}$ indicating the specificity in the mechanisms of action of these QTLs. Studying the effect of QTLs in different types of arthritis models may potentially give invaluable information on the regulatory mechanism of the QTLs.

Here, we characterized the effect of Ltab-Ncr3 on different models of arthritides, including both adjuvantinduced models [using mineral oil (IFA), hexadecane, heptadecane, and squalene for induction] and an antigendependent arthritis model (using CII in IFA for induction). Interestingly, we found that Ltab-Ncr3 is rather specific in its arthritis regulation. Because some arthritis loci are shared with other disease models such as experimental autoimmune encephalomyelitis (EAE), ${ }^{22}$ we further investigated if $L t a b$ $N c r 3$ has an impact on disease in two models of EAE. We finally assessed the effect of Ltab-Ncr3 on antigen-specific recall responses, using CII or ovalbumin as the antigens.

\section{Materials and Methods}

\section{Animals}

Inbred dark Agouti (DA)/Ztm rats were obtained from the Zentralinstitut für Versuchstierzucht (Hannover, Germany) and DA/OlaHsd rats from Harlan Europe (Horst, the Netherlands). ${ }^{23}$ Rats were maintained by sister-brother mating in a barrier facility at Scheele Laboratory, Karolinska Institutet, and were specific pathogen free according to the Federation of European Animal Laboratory Science Associations guidelines. All animals were housed in a climate-controlled environment with 14 hours light/10 hours dark cycles, in individually ventilated microisolator cages (Allentown Inc., Allentown, NJ) containing wood shavings (Tapvei, Scanbur, Sollentuna, Sweden), and fed standard rodent chow (R70; Lantmännen, Stockholm, Sweden) and had free access to water. Congenic strains were originally established on DA/Ztm background $(\mathrm{N}>20)$ and thereafter backcrossed further $(\mathrm{N}>5)$ to DA/OlaHsd, that is, wildtype (wt) DA. The recombinant congenic strains were generated by crossing F1 hybrid rats. Congenic strains with MHC haplotype $\mathrm{RT} 1^{\mathrm{h}}$ were derived from DA.1H (established at Zentralinsitut für Versuchstierzucht) which originates from the KHW strain. Genotyping was performed as previously described. ${ }^{9,24}$ Unless otherwise specified, 8- to 12-week-old, age- and sex-matched congenic and wt controls have been used in all experiments.

\section{Disease Induction and Evaluation}

All of the diseases were induced by an intradermal injection at the base of the tail as follows. PIA was induced by an intradermal injection of $100 \mu \mathrm{L}$ pristane (2,6,10,14-tetramethylpentadecane; Acros Organics, Morris Plains, NJ) at the base of the tail. OIA was induced by intradermal injection of $150 \mu \mathrm{L}$ IFA (Difco, Detroit, MI). Hexadecane-, heptadecane-, squalene-, and arlacel-induced arthritis were induced by an intradermal injection of $200 \mu \mathrm{L}$ of the adjuvants (all purchased from Sigma-Aldrich, St. Louis, MO). Pepsin-digested CII from rat chondrosarcoma was prepared as previously described. ${ }^{21}$ CIA was induced by intradermal injection of $100 \mu \mathrm{g}$ CII dissolved in $0.1 \mathrm{~mol} / \mathrm{L}$ acetic acid and emulsified in an equal volume of IFA. With the use of a macroscopic scoring system, arthritis development was assessed with the identity of the rats blinded for the investigator (A.C.Y.Y.). One point is given for each inflamed knuckle or toe, and up to five points were given for an affected ankle (maximum score per limb 15 and 60 for a rat). Weight change was used as an objective measurement of disease severity.

EAE was induced in DA.1HR7 by $10 \mathrm{mg}$ rat spinal cord homogenate in an equal volume of IFA and in DA.1HR56 by $50 \mu \mathrm{g}$ myelin oligodendrocyte glycoprotein (MOG) peptide ${ }_{91-108}$ emulsified in an equal volume of IFA. EAE development was assessed with the identity of the rats blinded for the investigators (A.C.Y.Y. and J.T.). As previously described, ${ }^{25}$ EAE was monitored on a scoring scale as follows: $0=$ normal; $1=$ tail weakness; $2=$ tail paralysis; $3=$ mild waddling movement; $4=$ heavy waddling movement, unsecure foothold; $5=$ paralysis of a limb, crawling; $6=$ paralysis of a pair of limbs; $7=$ paralysis of all four limbs; and $8=$ death. Animals were euthanized when they reached score 7 . 
All experiments were approved by the Stockholm Ethical Committee and performed in accordance with the guidelines of the Swedish National Board for Laboratory Animals and the European Community Council Directive (86/609/EEC).

\section{T-Cell Transfer}

Complete medium was prepared using Dulbecco's modified Eagle's medium (Gibco, Carlsbad, CA) supplemented with 5\% (v/v) fetal calf serum (Gibco), $50 \mu \mathrm{mol} / \mathrm{L} \beta$-mercaptoethanol (Gibco), $10 \mathrm{mmol} / \mathrm{L}$ HEPES (Gibco), $10 \mathrm{U} / \mathrm{mL}$ penicillin, and $100 \mu \mathrm{g} / \mathrm{mL}$ streptomycin (both from Invitrogen Life Technologies, Carlsbad, CA). Eight days after injection of the congenic and wt DA rats with IFA, draining lymph node cells from donor rats were harvested and cultured at a cell density of $3 \times 10^{6} / \mathrm{mL}$ in complete medium with $3 \mu \mathrm{g} / \mathrm{mL}$ concanavalin A (Sigma-Aldrich) at $37^{\circ} \mathrm{C}$ and $5 \% \mathrm{CO}_{2}$. After 65 hours, cells were washed and resuspended in Dulbecco's phosphate-buffered saline (PBS; Thermo Fisher Scientific, Waltham, MA). Cells $\left(3 \times 10^{7}\right)$ were injected intravenously into each recipient rat.

\section{In Vitro Antigen Restimulation and Cytokine ELISA}

Ovalbumin (600 $\mu \mathrm{g}$; Sigma-Aldrich) in PBS or $100 \mu \mathrm{g}$ CII in $0.1 \mathrm{~mol} / \mathrm{L}$ acetic acid emulsified in an equal volume of IFA was injected intradermally into each rat. Lymph nodes were harvested 10 days after immunization. Lymph node cells $\left(1 \times 10^{6}\right)$ in complete medium were added per well and cultured in $50 \mu \mathrm{g} / \mathrm{mL}$ ovalbumin, $10 \mu \mathrm{g} / \mathrm{mL}$ CII, or medium alone at $37^{\circ} \mathrm{C}$ for 88 hours. For cytokine enzymelinked immunosorbent assay (ELISA), Nunc MaxiSorp flat-bottom 96-well plate was first coated with $2 \mu \mathrm{g} / \mathrm{mL}$ antirat interferon (IFN)- $\gamma$ (clone: DB1; BioLegend, San Diego, $\mathrm{CA}$ ) and $2 \mu \mathrm{g} / \mathrm{mL}$ anti-mouse IL-17 (PN 840525; R\&D Systems, Minneapolis, MN), respectively, and incubated at $4{ }^{\circ} \mathrm{C}$ overnight. After blocking and washing with PBS/ Tween $(0.05 \%), 50 \mu \mathrm{L}$ supernatant fluid and cytokine standard were added to plate and incubated at room temperature for 2 hours. The plate was then washed with PBS/Tween $(0.05 \%)$ and incubated with biotinylated $0.5 \mu \mathrm{g} / \mathrm{mL}$ anti-rat IFN- $\gamma$ (Poly5109; BioLegend) and $0.4 \mu \mathrm{g} / \mathrm{mL}$ anti-mouse IL-17 (PN 840526; R\&D Systems), respectively, for detection. For detection of cytokines IL-10 and TNF, we used the rat IL-10 DuoSet ELISA (DY522; R\&D Systems) and rat TNF ELISA set (catalog no. 558535; BD Biosciences, San Jose, CA), respectively, according to the manufacturer's instructions. Eu $3^{+}$-conjugated streptavidin (dissociation-enhanced lanthanide fluorescence immunoassay) was used for signal detection, performed on a Synergy 2 multimode plate reader (BioTek, Winooski, VT).

\section{Serum ELISA}

Levels of CII-specific antibodies in CIA serum were determined by ELISA as previously described. ${ }^{21}$ Briefly,
SpectraPlates-96HB (PerkinElmer, Waltham, MA) were coated with $10 \mu \mathrm{g} / \mathrm{mL}$ rat CII. Biotinylated isotype-specific anti-rat monoclonal antibodies against $\operatorname{IgG}_{1}$ (clone RG11/ 39.4; BD Pharmingen, San Jose, CA) and $\mathrm{IgG}_{2 \mathrm{~b}}$ (clone RG7/11.1; BD Pharmingen) were used as secondary reagents. Anti-CII antibodies were detected in a heterogenous time-resolved fluorometric assay (Victor/1420 Multilabel counter; Wallac, Wellesley, MA), and $\mathrm{Eu}^{3+}$-conjugated streptavidin (dissociation-enhanced lanthanide fluorescence immunoassay) was used as a secondary reagent. The disease marker $\alpha 1$-acid glycoprotein (AGP) in serum diluted 1:20,000 was measured by the AGP ELISA kit (Life Diagnostics, West Chester, PA).

\section{Flow Cytometry}

Single-cell suspensions were prepared in ice-cold fluorescence-activated cell sorting buffer $\left(\mathrm{Ca}^{2+}\right.$-and $\mathrm{Mg}^{2+}$-free Dulbecco's PBS supplemented with $1 \%$ fetal calf serum, $10 \mathrm{mmol} / \mathrm{L}$ EDTA) and stained with a saturating concentration of monoclonal antibodies on 96-well V-bottom polypropylene plates (BD Biosciences). The following antibodies were used: CD4 (OX35) was purchased from BioLegend; CD25 (OX39) was purchased from BD Pharmingen; $\alpha \beta$ TCR (R73), Foxp3 (FJK-16s), and Ki-67 (SolA15) were purchased from eBioscience (San Diego, CA). After extracellular staining, cells were incubated in fixation/permeabilization buffer (eBioscience) and washed with permeabilization buffer (eBioscience) before intracellular staining of Foxp3 and Ki-67. Both LIVE/DEAD Violet (Invitrogen, Carlsbad, CA) and the forward scatter versus side scatter plot were used to include only nonnecrotic cells. A SORP BD LSR II analytic flow cytometer (BD Biosciences) was used for acquisition, and the data were analyzed with FlowJo software version 8.8.6 (Tree Star, Ashland, OR).

\section{Histology}

Rats were sacrificed at the end of the arthritis experiment. Hind paws without skin were fixed for 4 days in $4 \%$ phosphate-buffered formaldehyde, decalcified with EDTA, and embedded in paraffin. Tissue sections were stained with hematoxylin and eosin. Hematoxylin and eosin slides were assessed with the identity of the rats obscured. Histology scores were given to synovium, cartilage, bone, and joint architecture. For synovium, 0,1 , or 2 points were given to each of the following five criteria, depending on the severity, hyperplasia, infiltration, angiogenesis, pannus formation, and necrosis. For cartilage erosions, 0 , 1, or 2 points were given to each of the following two criteria: erosion and new formation. For bone erosions, 0, 1, or 2 points were given to each of the following two criteria: erosion and new bone formation. For joint destruction, 0,3 , or 6 points were given to each of the following two criteria: namely destruction of joints and ankylosis. The score for synovium 


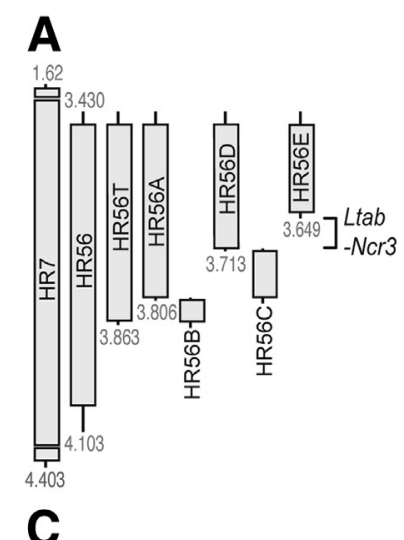

B
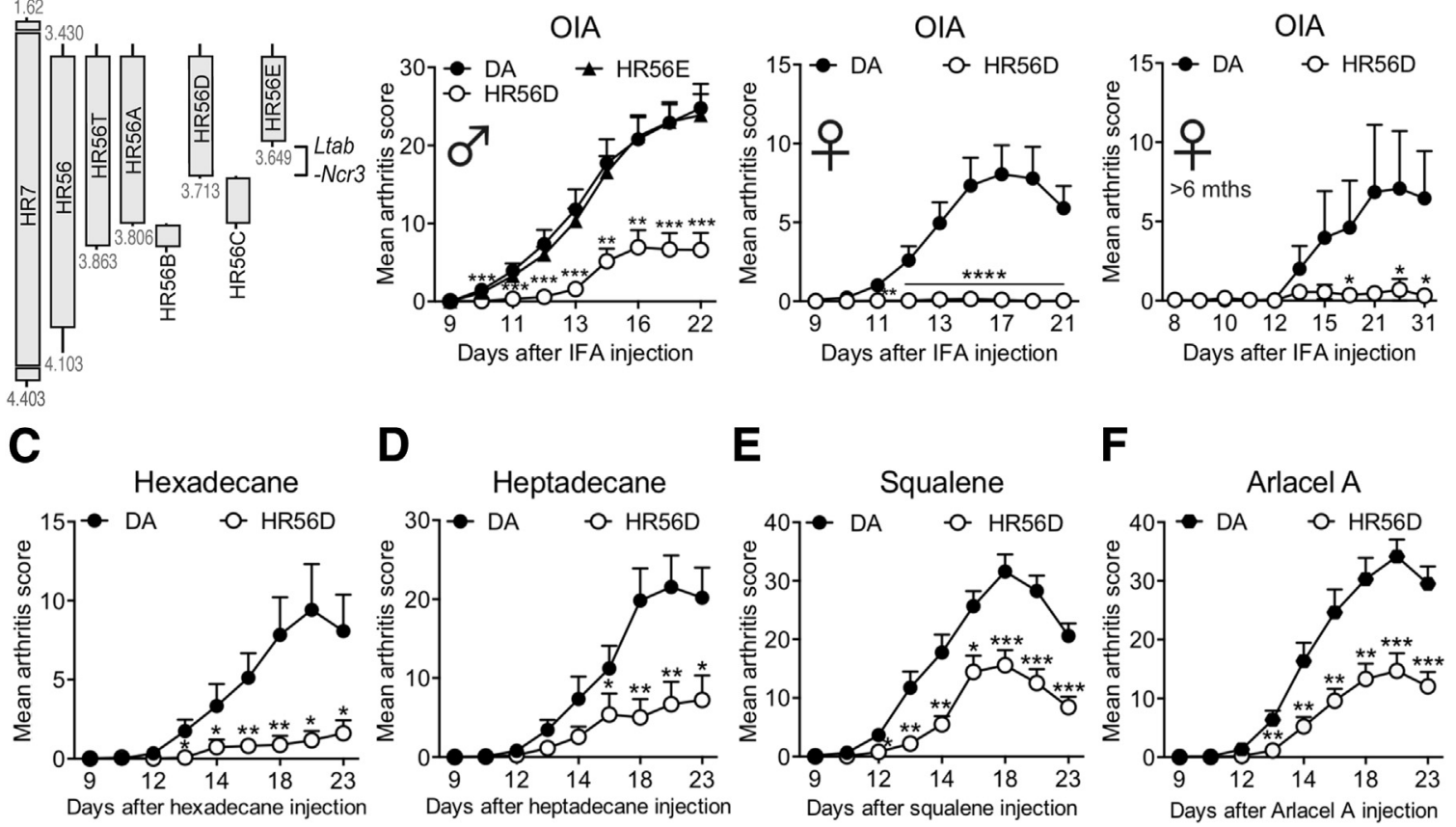

Figure 1 Ltab-Ncr3 regulates oil-induced arthritis (OIA) and arthritis induced by other oil adjuvants. A: Graphical illustration of the mapping of different congenic strains on rat chromosome 20, based on UCSC genome browser (University of California-Santa Cruz, Santa Cruz, CA; https://genome.ucsc.edu) 2004 (Baylor 3.4/rn4) assembly. Positions are indicated in megabases. B: Development of 0IA in DA.1HR56D, DA.1HR56E, and wild-type DA rats as assessed by macroscopic arthritis score and histopathology. Disease data of other congenic strains are shown in Supplemental Figure S2. B: Macroscopic arthritis scores for males (left), females (center), and females older than 6 months (right). C: Hexadecane-induced arthritis in DA.1HR56D and DA rats. D: Heptadecane-induced arthritis in DA.1HR56D and DA rats. E: Squalene-induced arthritis in DA.1HR56D and DA rats. F: Arlacel-A-induced arthritis in DA.1HR56D and DA rats. Data are expressed as means \pm SEM. $n=15$ male DA.1HR56D, $n=20$ male DA.1HR56E, and $n=14$ male DA rats (B, left); $n=21$ female DA.1HR56D and female DA rats (B, center); $n=13$ female ( $>6$ months) DA.1HR56D and $n=13$ female ( $>6$ months) DA rats (B, right); $n=12$ DA.1HR56D rats and $n=15$ DA rats $($ C); $n=12$ DA.1HR56D and $n=15$ DA rats (D); $n=19$ DA.1HR56D and DA rats (E); $n=14$ DA.1HR56D and $n=16$ DA rats $(\mathbf{F}) .{ }^{*} P<0.05,{ }^{* *} P<0.01, * * * P<0.001$, and $* * * * P<0.0001$ compared with wild-type DA. Statistics were determined with the $U$ test. DA, dark Agouti; IFA, incomplete Freund's adjuvant.

(10), cartilage (4), bone (4), and joint structure (12) add up to 30 points. In addition, the tissue sections were stained with May-Grünwald Giemsa to study synovial inflammatory infiltrates, and with Safranin O and Toluidine blue to study cartilage destruction.

\section{Statistical Analysis}

The significance of differences in arthritis disease incidence was evaluated by Fisher's exact test. All other statistical analyses were evaluated by $U$ test and performed on Prism version 6.0 (GraphPad, San Diego, CA).

\section{Results}

Ltab-Ncr3 Is Associated with OIA, Independent of Sex and Age

We have previously shown that the 33-kb interval Ltab$N c r 3$ in the MHC-III region regulates PIA. ${ }^{9}$ We first tested if Ltab-Ncr3 had a specific impact on PIA or if it could also influence other models of arthritis, such as OIA.

We recently showed that the severity of PIA does not correlate with the amount of pristane administered and that severe arthritis can be induced with doses as small as $5 \mu \mathrm{L}$ pristane. ${ }^{13}$ In addition, no sex bias has been reported in PIA for DA rats. However, we found a clear dose and sex dependence in OIA. We found that administration of $300 \mu \mathrm{L}$ IFA induced more severe arthritis than $100 \mu \mathrm{L}$ in both male and female rats (Supplemental Figure S1, A-C). Furthermore, male DA rats were more prone to severe arthritis than age-matched female rats (Supplemental Figure S1, A and C). From these data, we used different doses of IFA in male $(150 \mu \mathrm{L})$ and female $(300 \mu \mathrm{L})$ rats in subsequent experiments to induce OIA.

We assessed the development of OIA in different MHCIII congenic strains (Figure 1A). Strains with congenic fragments overlapping the Ltab-Ncr3 locus (ie, DA.1HR56, DA.1HR56T, DA.1HR56A, and DA.1HR56D) developed milder arthritis than DA rats as evident by lower disease scores, lower disease incidence, and a delayed disease onset. By contrast, strains with congenic fragments outside the Ltab-Ncr3 locus (DA.1HR56B, DA.1HR56C, and DA.1HR56E) did not show any protection (Figure 1B, Supplemental Figure S2, Table 1). The arthritis regulatory effect of Ltab-Ncr3 was not affected by sex or age. Histologic analyses of the synovial joints from rats with OIA further supported the reduced clinical arthritis severity 
Table 1 Summary of Ltab-Ncr3 Congenic Effects on OIA in Male and Female Rats

\begin{tabular}{|c|c|c|c|c|c|c|c|c|c|c|c|}
\hline \multirow[b]{2}{*}{ Strain } & \multirow[b]{2}{*}{ Sex } & \multirow[b]{2}{*}{$\mathrm{AUC}^{\dagger}$} & \multirow[b]{2}{*}{$\Delta$ Weight, $\%^{\ddagger}$} & \multirow[b]{2}{*}{ Onset, day ${ }^{\S}$} & \multicolumn{5}{|c|}{ Joint histology } & \multirow[b]{2}{*}{$\begin{array}{l}\text { Incidence, } \\
\%\end{array}$} & \\
\hline & & & & & $\begin{array}{l}\text { Synovium } \\
(\max 10)\end{array}$ & $\begin{array}{l}\text { Cartilage } \\
(\max 4)\end{array}$ & Bone $(\max 4)$ & $\begin{array}{l}\text { Joint } \\
\text { (max 12) }\end{array}$ & $\begin{array}{l}\text { Total } \\
(\max 30)\end{array}$ & & $\mathrm{Nc}$ \\
\hline DA.1HR56" & M & $58 \pm 18^{* *}$ & $1.9 \pm 1.4$ & $12.2 \pm 0.5^{*}$ & ND & ND & ND & ND & ND & 73 & 15 \\
\hline \multirow[t]{2}{*}{ DA.1HR56T" } & M & $54 \pm 13^{* *}$ & $4.3 \pm 1.0^{* *}$ & $13.4 \pm 0.8^{* * *}$ & ND & ND & ND & ND & ND & 94 & 18 \\
\hline & $\mathrm{F}$ & $32 \pm 13^{* * *}$ & $2.7 \pm 1.0^{* *}$ & $12.5 \pm 0.6$ & ND & ND & ND & ND & ND & 75 & 20 \\
\hline \multirow[t]{2}{*}{ DA.1HR56A" } & M & $64 \pm 22^{* *}$ & $2.0 \pm 2.0^{*}$ & $12.7 \pm 0.6^{*}$ & $5.6 \pm 0.7$ & $1.2 \pm 0.3^{* *}$ & $1.0 \pm 0.3^{* *}$ & $0.8 \pm 0.6^{* *}$ & $8.6 \pm 1.4^{* *}$ & 67 & 15 \\
\hline & $\mathrm{F}$ & $26 \pm 10^{* * * *}$ & $2.9 \pm 0.8^{* *}$ & $12.3 \pm 0.3$ & ND & ND & ND & ND & ND & 67 & 24 \\
\hline \multirow[t]{2}{*}{ DA.1HR56D" } & M & $55 \pm 17^{* * * *}$ & $1.8 \pm 1.5^{* \star * *}$ & $13.0 \pm 0.6^{* *}$ & $5.6 \pm 1.0$ & $0.7 \pm 0.4^{* * *}$ & $0.7 \pm 0.4^{* * *}$ & $1.0 \pm 0.4^{* *}$ & $8.0 \pm 2.0^{* *}$ & 87 & 15 \\
\hline & $\mathrm{F}$ & $1 \pm 0^{* * * *}$ & $1.8 \pm 0.5$ & $13.7 \pm 1.8$ & ND & ND & ND & ND & ND & 14 & 21 \\
\hline \multirow[t]{2}{*}{ DA.1HR56B } & M & $198 \pm 22$ & $-8.2 \pm 1.6$ & $11.4 \pm 0.4$ & $8.2 \pm 0.6$ & $3.7 \pm 0.3$ & $3.4 \pm 0.4$ & $5.3 \pm 1.5$ & $20.7 \pm 2.5$ & 100 & 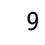 \\
\hline & $\mathrm{F}$ & $89 \pm 23$ & $0.9 \pm 1.5$ & $10.7 \pm 0.3$ & ND & ND & ND & ND & ND & 83 & 18 \\
\hline DA.1HR56C & M & $210 \pm 21$ & $-11.6 \pm 2.1$ & $10.9 \pm 0.3$ & ND & ND & ND & ND & ND & 100 & 13 \\
\hline DA.1HR56E & M & $199 \pm 21$ & $-9.8 \pm 1.7$ & $10.5 \pm 0.3$ & $8.3 \pm 0.5$ & $2.8 \pm 0.3$ & $3.1 \pm 0.3$ & $4.9 \pm 0.9$ & $19.0 \pm 1.4$ & 90 & 20 \\
\hline \multirow[t]{2}{*}{ DA } & M & $207 \pm 29$ & $-9.8 \pm 1.7$ & $10.9 \pm 0.5$ & $7.2 \pm 0.5$ & $2.8 \pm 0.3$ & $2.8 \pm 0.3$ & $5.5 \pm 0.9$ & $18.2 \pm 1.8$ & 100 & 14 \\
\hline & $\mathrm{F}$ & $98 \pm 15$ & $-1.1 \pm 1.0$ & $11.5 \pm 0.3$ & ND & ND & ND & ND & ND & 100 & 2 \\
\hline
\end{tabular}

Values for AUC, weight change, day of onset, and joint histology score are expressed as means \pm SEM.

${ }^{*} P<0.05,{ }^{* *} P<0.01,{ }^{* * *} P<0.001$, and ${ }^{* * * *} P<0.0001$, relative to wt DA rats. Statistics were determined with the $U$ test.

${ }^{\dagger} A U C$ indicates the area under the arthritis score curve obtained until day 21 after IFA injection.

${ }^{\ddagger} \Delta$ Weight (\%) indicates percentage change in weight on day 21 to 22 versus day 9 .

${ }^{\S}$ Day of disease onset is the first day when any clinical signs of arthritis in the rats could be observed.

"Incidence indicates the percentage of animals that develop arthritis for at least two consecutive scoring days.

"Congenic strains that overlap the Ltab-Ncr3 locus and display arthritis protection phenotype.

F, female; M, male; AUC, area under curve; DA, dark Agouti; IFA, incomplete Freund's adjuvant; ND, not determined; OIA, oil-induced arthritis; wt, wild-type.

observed in DA.1HR56D rats (Figure 2, Table 1). We found that the histologic architecture was severely damaged in DA.1HR56E and DA rats with pronounced synovial hyperplasia and pannus formation, synovial inflammation, and extensive bone erosion and cartilage destruction. On the contrary, DA.1HR56D preserved a nearly normal histologic architecture with minimal synovial hyperplasia or pannus formation, significantly reduced synovial inflammatory cells, and minimal erosion in bone and cartilage.

\section{Ltab-Ncr3 Regulates a Broad Set of Adjuvant-Induced Arthritis Models}

Next, we investigated if Ltab-Ncr3 regulates other hydrocarbon oil-based arthritis models. One such model is squalene-induced arthritis (SIA). The endogenous adjuvant squalene is a biochemical precursor of cholesterol and other steroids and induces T-cell-mediated arthritis in DA rats. ${ }^{26}$ Other hydrocarbon adjuvants, including hexadecane and heptadecane, which consists of unbranched carbon chains, have also been used to induce arthritis in DA rats. ${ }^{27}$ Here, we showed that despite differences in arthritic potency, ${ }^{27}$ administration of these adjuvants (squalene, hexadecane, and heptadecane) to DA.1HR56D rats consistently resulted in less severe arthritis than when administered to DA rats (Figure 1, C-E). In addition, we found that Ltab-Ncr3 also regulates arlacel-induced arthritis (Figure $1 \mathrm{~F}$ ), induced by mannide monooleate (also called arlacel A), an emulsifying agent in IFA. Thus, we showed that, in addition to PIA and OIA, Ltab-Ncr3 regulates arthritis induced by several other adjuvants.

\section{Ltab-Ncr3 Regulates the Priming of T Cells in OIA}

To assess whether Ltab-Ncr3 regulates arthritis priming and whether the protective effect of Ltab-Ncr3 can be transferred by these $\mathrm{T}$ cells, we performed adoptive transfer of $\mathrm{T}$ cells from IFA-injected rats. When we transferred the $\mathrm{T}$ cells from IFA-injected Ltab-Ncr3 congenic and wt DA donor rats to naive heterozygous recipient rats, we showed that $\mathrm{T}$ cells originating from congenic rats were less arthritogenic than $\mathrm{T}$ cells from wt DA rats (Figure 3), indicating that Ltab-Ncr3 regulates the priming of the $\mathrm{T}$ cells in OIA. Because lymph node cells were harvested on day 8 after IFA injection, the Ltab-Ncr3 arthritis regulatory effect already took place before day 8 (mean day of arthritis onset in DA rats is 11 days after IFA injection) (Table 1).

\section{Ltab-Ncr3 Does Not Have an Effect on Collagen-Induced Arthritis}

Having shown that Ltab-Ncr3 regulates different hydrocarbon oil-induced arthritis models, such as PIA, OIA, and SIA; we next investigated the association of Ltab-Ncr3 to antigen-induced arthritis model CIA. We used a standard protocol for the induction of CIA in DA rats, ${ }^{21}$ which is rat CII emulsified in IFA without the use of Mycobacterium tuberculosis. Thus, the same adjuvant component (ie, IFA) is used in both OIA and CIA.

We found that both Ltab-Ncr3 congenic and wt DA rats developed severe CIA with comparable disease scores (Figure 4A) and similar levels of anti-CII antibodies of both $\mathrm{IgG}_{1}$ and $\mathrm{IgG}_{2 \mathrm{~b}}$ isotypes (Figure $4 \mathrm{~B}$ ). In addition, both 


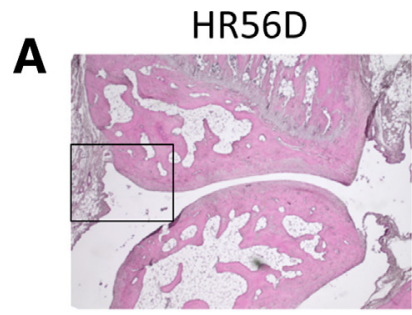

B

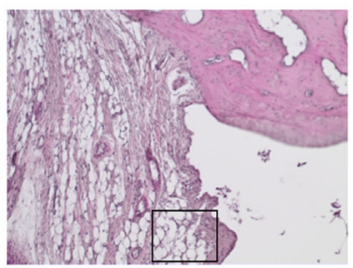

C

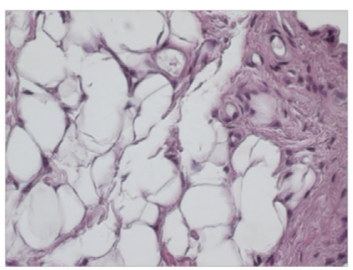

D

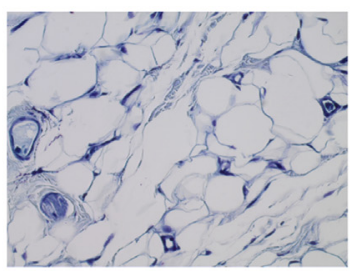

E

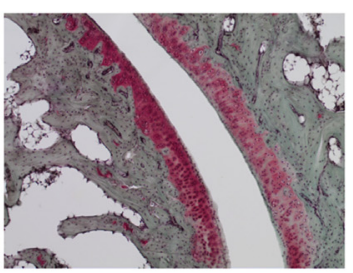

$\mathbf{F}$

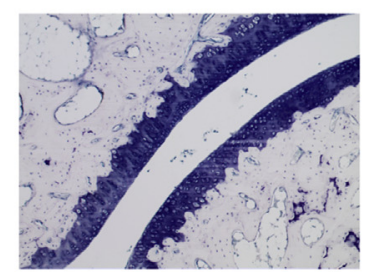

HR56E
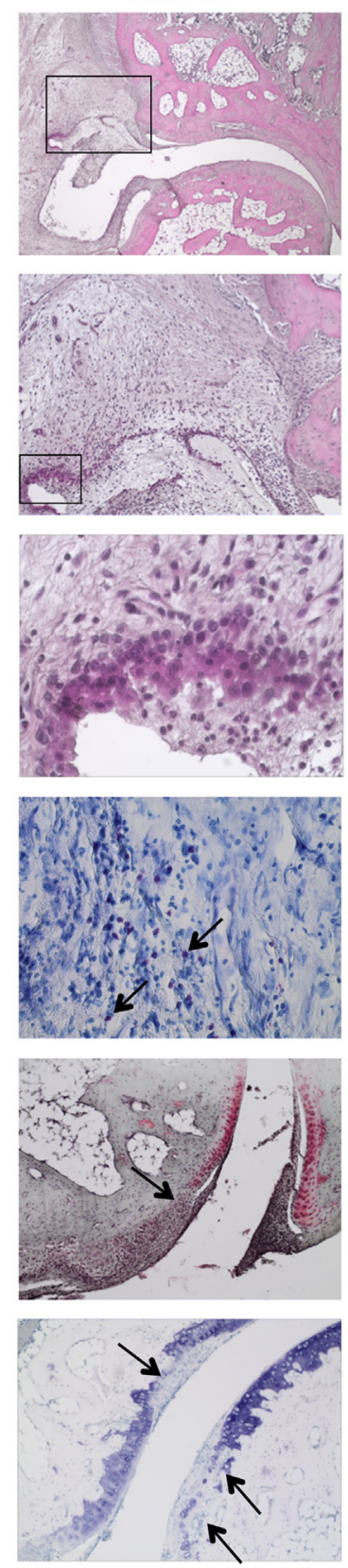

DA
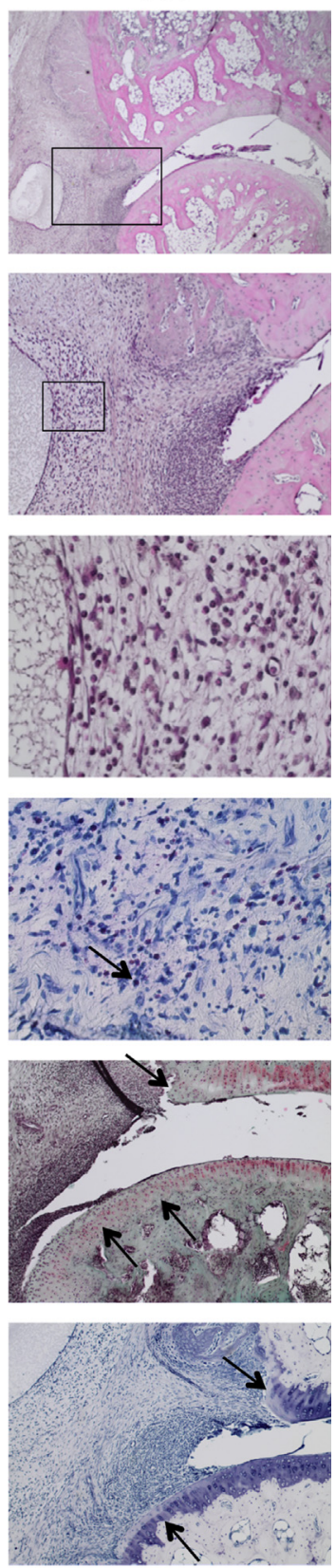

Figure 2 Ankle histologic characteristics of DA.1HR56D, DA.1HR56E, and DA rats on day 24 after incomplete Freund's adjuvant injection. A-C: Hematoxylin and eosin staining of synovial joint (A), of the boxed area in panel $\mathbf{A}(\mathbf{B})$, and of the boxed area in panel B (C). DA.1HR56E and DA ankle joints display massive cell infiltration, pannus formation, as well as cartilage destruction and bone erosion; whereas DA.1HR56D ankles have a near-normal histologic architecture. D: May-Grünwald Giemsa staining shows more pronounced inflammatory infiltrates (indicated with arrows) in DA.1HR56E and DA synovium. $\mathbf{E}$ and F: Safranin 0 (E) and Toluidine blue (F) staining shows increased cartilage degradation (indicated with arrows) of synovial joints in DA.1HR56E and DA. Cartilage is orange/red when stained with Safranin 0 , and purple when stained with Toluidine blue. Original magnification: $\times 2.5(\mathbf{A}) ; \times 10(\mathbf{B}, \mathbf{E}$, and F); $\times 40$ (C and D). DA, dark Agouti. congenic and wt DA rats with CIA displayed comparable serum level of acute-phase protein AGP (Figure 4C), unlike congenic rats with OIA which showed reduced serum level of AGP (Figure 4D). Because the arthritis-modulating effect of the Ltab-Ncr3 haplotype could have been obscured by a too high dose of antigen, we repeated the experiment using lower doses of CII while maintaining the same dose of IFA. As expected, rats injected with lower doses of CII (75 $\mu \mathrm{g}$, $50 \mu \mathrm{g}$, and $25 \mu \mathrm{g}$ of CII instead of the 100- $\mu \mathrm{g}$ standard dose) developed gradually less severe CIA (Supplemental Figure S3). However, there was still no difference in disease severity between congenic and wt DA rats (Supplemental Figure S3).
The disease development in CIA differs from OIA and other adjuvant-induced arthritides in several aspects. First, the clinical onset of CIA is around 14 days after induction, which is later than in OIA which typically starts around 11 days after induction (Figure 4E). In addition, CIA develops into a more aggressive disease, leading to massive edema affecting the entire paw, whereas OIA often affects the ankle joint or the metacarpophalangeal joints of the knuckles (as in PIA $^{13}$ ). Here, we found that the congenic rats developed milder arthritis with a later disease onset in OIA and SIA but not CIA (Figure 4, E and F). Thus, Ltab$N c r 3$ appears to have a specific role in controlling the response to adjuvants. 
A

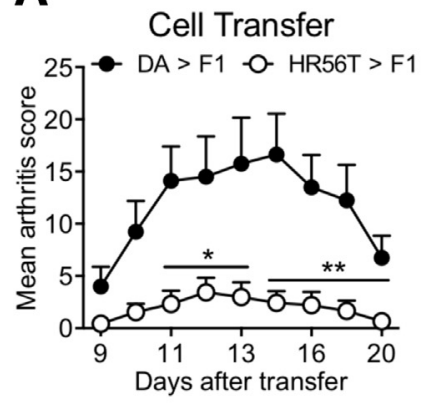

B

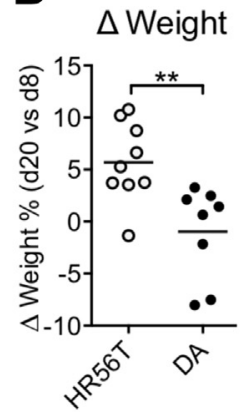

C

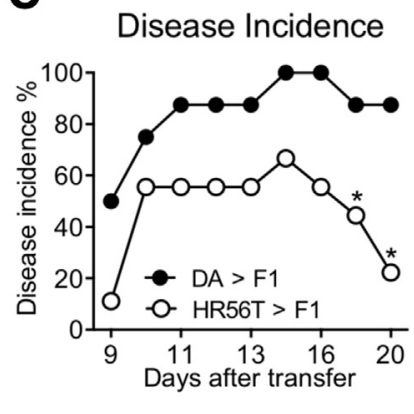

Figure $3 \quad$ Ltab-Ncr3 regulates the priming of oil-induced arthritis. A-C: Development of arthritis of the heterozygous (F1) recipient rats after transfer of T cells from incomplete Freund's adjuvant (IFA)-injected congenic DA.1HR56T or DA donor rats. Data are expressed as mean arthritis scores \pm SEM (A), weight change percentage (day 20 versus day $8, \mathbf{B})$, and disease incidence $(\%, C)$. $n=9$ DA.1HR56T donor rats; $n=8$ DA donor rats. ${ }^{*} P<0.05,{ }^{*} P<0.01$. The significance of differences in arthritis disease incidence was evaluated by Fisher's exact test. Other statistics were determined with the $U$ test. DA, dark Agouti.

\section{Ltab-Ncr3 Is Not Associated with EAE}

Several arthritis loci have been identified in other inflammatory disease models, such as EAE, ${ }^{22}$ a chronic relapsing model of multiple sclerosis. Thus, we asked whether Ltab$N c r 3$ would regulate the development of EAE, in particular because the MICB-LSTI region in humans has been shown to be associated with multiple sclerosis in humans. ${ }^{28}$ However, regardless of whether we used rat spinal cord homogenate or MOG peptide ${ }_{91-108}$ for immunization, the Ltab-Ncr3 congenic strains developed the same degree of severity of EAE as that of the wt DA rats (Figure 5). We concluded that Ltab-Ncr3 does not regulate EAE.

\section{Ltab-Ncr3 Has No Effect on T-Cell Response to Antigens}

All of the data so far showed that Ltab-Ncr3 regulates T-cell priming in arthritis induced by hydrocarbon adjuvants and that this effect is abolished when immunizing with a protein antigen. We determined antigen-specific recall response in congenic and wt DA rats immunized with CII, or a nonarthritogenic antigen ovalbumin, by restimulating draining lymph node cells in vitro with the same antigen 10 days after immunization. As measured by interferon IFN- $\gamma$ and IL-17 secretion, we showed that there was no difference in the T-cell response between DA.1HR56D and wt DA rats on in vitro restimulation with rCII (Figure 6A) or ovalbumin (Figure 6B). In addition, no difference was found in IL-10 and TNF secretion between DA.1HR56D and wt DA rats (Supplemental Figure S4). In other words, Ltab-Ncr3 does not regulate $\mathrm{T}$-cell response to antigens used for immunization and measured for recall response ex vivo.

\section{Ltab-Ncr3 Congenic-Derived T Cells Are Less Proliferative and Produce Less Proinflammatory Cytokines in OIA but Not in CIA}

We have recently shown that disease-promoting MHC-II alleles in PIA drive T helper (Th1)-type immunity and that

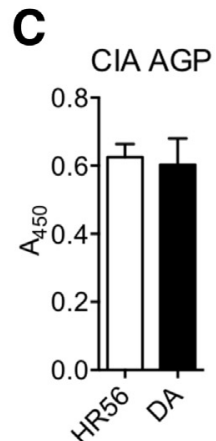

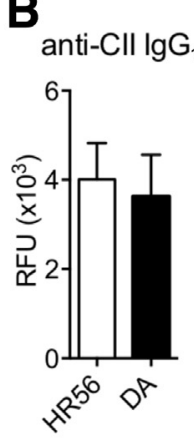

D

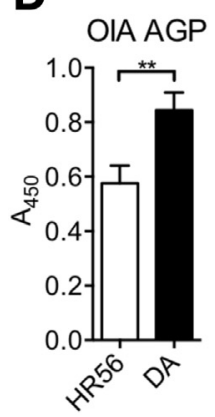

E

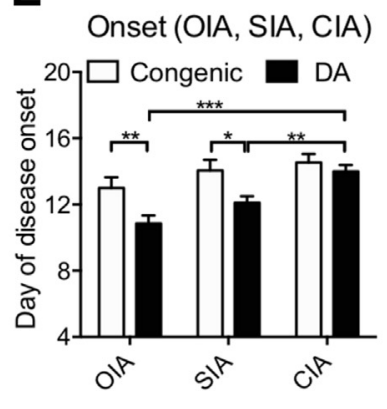

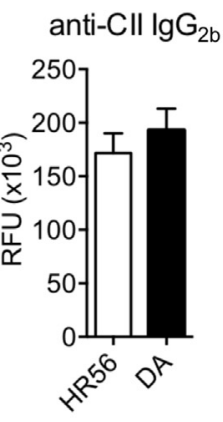

$\mathbf{F}$
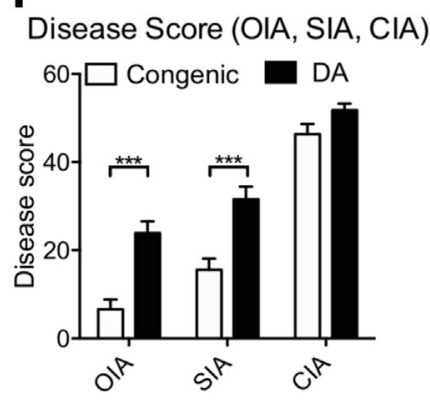

Figure 4 Ltab-Ncr3 does not regulate collageninduced arthritis (CIA). A-C: Development of CIA shown as mean arthritis score (A), level of serum anti-collagen type II (CII) antibodies of $\mathrm{IgG}_{1}$ isotype and $\mathrm{IgG}_{2 b}$ isotype (B), and level of serum a1-acid glycoprotein (AGP) in DA.1HR56 and DA rats on day 24 after CII injection (C). D: Level of serum AGP in DA.1HR56 and DA rats with oilinduced arthritis (OIA). E and F: Comparison of day of disease onset (E) and peak mean arthritis score of the Ltab-Ncr3 congenic and DA rats $(\mathbf{F})$ in OIA, squalene-induced arthritis (SIA), and CIA. Data are expressed as means \pm SEM. $n=13$ DA.1HR56 rats (C); $n=15$ DA rats (C); $n=23$ DA.1HR56 rats (D); $n=28$ DA rats (D). ${ }^{*} P<0.05$, ${ }^{* *} P<0.01$, and ${ }^{* * *} P<0.001$ compared with the controls. Statistics were determined with the $U$ test. DA, dark Agouti. 

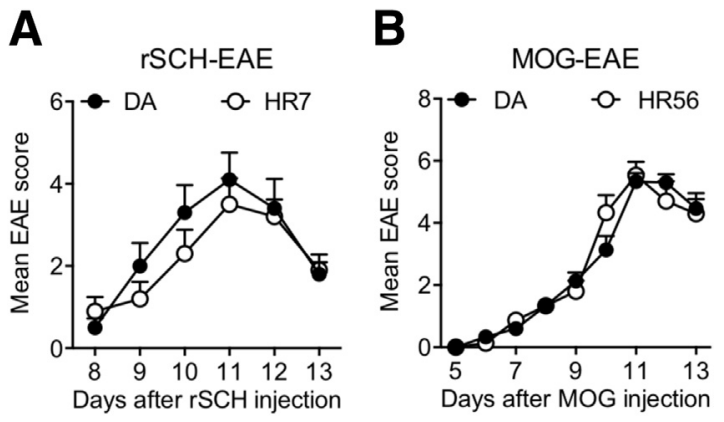

Figure 5 Ltab-Ncr3 does not regulate experimental autoimmune encephalomyelitis (EAE). A and B: Development of EAE induced by rat spinal cord homogenate $(\mathrm{rSCH})$ in DA.1HR7 and DA rats $(\mathbf{A})$ and by myelin oligodendrocyte glycoprotein (MOG) peptide ${ }_{91-108}$ in DA.1HR56 and DA rats (B). Data are expressed as mean EAE scores \pm SEM. $n=10$ DA.1HR7 rats and $n=10$ DA rats (A); $n=15$ DA.1HR7 rats and $n=15$ DA rats (B). DA, dark Agouti.

neutralization of IFN- $\gamma$ (a Th1-associated cytokine) before the arthritis onset ameliorates disease. ${ }^{29}$ However, to which degree Th1-type responses are instrumental for the development of OIA has not been addressed. We further analyzed the lymph node cells from Ltab-Ncr3 congenic and wt DA rats 10 days after injection of IFA only (OIA) or with CII in IFA (CIA). Although the number of $\mathrm{CD}^{+}{ }^{+} \mathrm{T}$ cells was comparable between congenic and wt DA rats (data not shown), we found that IFA-injected congenic rats produced lower levels of IL-17 with a trend for lower levels of IFN- $\gamma$ (Figure 6C). In addition,
$\mathrm{T}$ cells, including regulatory $\mathrm{T}$ cells, from the IFA-injected congenic rats were less proliferative as determined by staining for Ki-67 (Figure 6D). Such reduction in proliferation and cytokine production in congenic rats could, however, only be found in OIA but not in CIA (Figure 6, C and D).

\section{Discussion}

We previously showed that the 33-kb haplotype Ltab-Ncr3 in the telomeric end of MHC-III regulates the onset, severity, and chronicity of PIA. ${ }^{9}$ In the present study, we further show that Ltab-Ncr3 also regulates other oil adjuvant-induced arthritis models such as OIA and SIA but not models induced by immunization with tissue-derived antigens such as CII or MOG. In contrast to the pronounced effect we showed for priming of arthritogenic $\mathrm{T}$ cells in the adjuvant models, there was no difference in antigen-specific T-cell recall responses in the Ltab-Ncr3 congenic rats on in vitro restimulation with the tissue antigens. The difference between these two types of models could not easily be explained by differences in downstream pathways, because CIA is known to be mediated by antibodies and EAE is dependent on effector T cells, whereas adjuvant arthritides operate by $\mathrm{T}$ cells. Thus, this difference is more likely to be related to the different types of T-cell activation that can be attributed to adjuvants, which likely expose a large number of endogenous antigens in vivo in
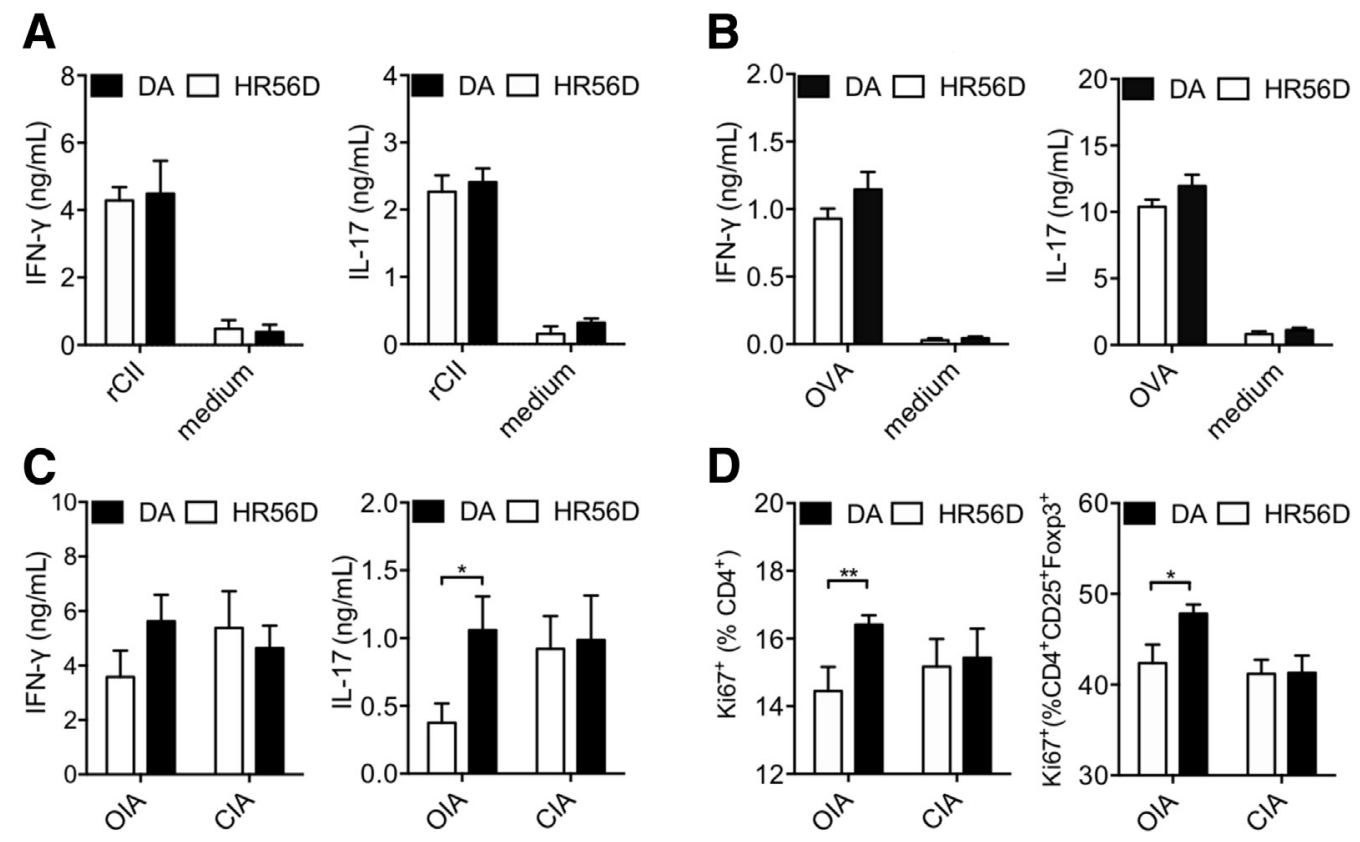

Figure 6 Ltab-Ncr3 has no effect on T-cell response to antigens. Ltab-Ncr3 congenic T cells are less proliferative and produce less proinflammatory cytokines in oil-induced arthritis (OIA) but not collagen-induced arthritis (CIA). A and B: DA.1HR56D and DA rats were immunized with collagen type II (CII) in incomplete Freund's adjuvant (IFA) (A) or ovalbumin (OVA) in IFA (B). Ten days after immunization, lymph node cells were restimulated with the same antigen in vitro for 88 hours, and levels of interferon (IFN)- $\gamma$ and IL-17 were determined in the supernatant fluid. DA.1HR56D and wild-type DA rats were injected with IFA only (OIA) or with CII in IFA (CIA). C: Ten days after injection, lymph node cells were stimulated with anti-CD3/CD28, and levels of cytokines IFN- $\gamma$ and IL-17 were determined in the supernatant fluid. D: Lymph node cells were also analyzed for percentage of Ki-67 ${ }^{+}$staining on CD4 ${ }^{+} \mathrm{T}$ cells and $\mathrm{CD}^{+}{ }^{+} \mathrm{CD} 25^{+}$Foxp $^{+}$T cells. Data are expressed as means \pm SEM. $n=7$ to 9 rats per group $(\mathbf{A}, \mathbf{C}$, and $\mathbf{D}) ; n=6$ rats per group $(\mathbf{B})$. ${ }^{*} P<0.05,{ }^{* *} P<0.01$ compared with wild-type DA. Statistics were determined with the $U$ test. DA, dark Agouti. 
comparison with the immunodominant effect of an administered exogenous antigen.

In a genetically susceptible rat strain such as DA, an intradermal injection of adjuvant alone (such as pristane ${ }^{13}$ and $\mathrm{IFA}^{10}$ ) can induce arthritis. The mechanisms involved in the disease development are not fully established, but it is known that the disease is driven by polyclonal $\mathrm{T}$ cells and the disease can be adoptively transferred by activated MHCII-restricted $\mathrm{CD}^{+} \alpha \beta$ T cells. $^{10-12}$ We have previously shown that the addition of an immunogenic cartilage protein, such as CII, to IFA leads to a qualitatively different type of disease. ${ }^{30}$ First, addition of an immunogenic protein antigen led to a different autoimmune response driven by the injected antigen rather than the adjuvant. This was clearly shown when nonarthritogenic ovalbumin was injected instead of CII; the rats did not develop arthritis at all, even though IFA alone is arthritogenic. However, addition of a nonimmunogenic protein, such as rat type I collagen, for which rats are tolerized, in IFA leads to an oil adjuvant type of disease. ${ }^{31}$ Second, CIA often develops a more aggressive disease course with massive edema in the entire paw, as well as a strong autoantibody response to CII, whereas OIA is milder with earlier onset than CIA and no or limited anti-CII antibody response. ${ }^{30}$ Third, although OIA and other adjuvant arthritides can be adoptively transferred by $\mathrm{T}$ cells, ${ }^{11}$ CIA cannot be effectively transferred by CIIreactive $\mathrm{T}$ cells (R.H., unpublished observation). CIA in rats is dependent on $\mathrm{T}$ cells both during priming and the later development of arthritis, ${ }^{32}$ but the effector stage of arthritis is less dependent on $\mathrm{T}$ cells but rather mediated by antibodies. This is in contrast to adjuvant arthritides, which is dependent on $\mathrm{T}$ cells for the inflammatory joint attack in which antibodies do not seem to play a pathogenic role. ${ }^{33}$

The specific association of Ltab-Ncr3 with adjuvantbased autoimmunity could explain why this locus has not been detected in arthritis linkage studies in mice, because CIA is the most commonly used arthritis model for such studies, and intradermal injection of adjuvants alone does not induce arthritis in mice. This could also partly explain why Ltab-Ncr3 did not regulate EAE, which was also induced by the immunization of an antigen (eg, MOG peptide). EAE is known to be possible to transfer with $\mathrm{T}$ cells and does not necessarily need $\mathrm{B}$ cells or antibodies in the effector stage. Combined with the observation that the Ltab-Ncr3 locus controlled the priming and T-cell activation, it shows that the mechanisms involved in the priming of $T$ cells with no administered exogenous antigen (in OIA and arthritis induced by oil adjuvants) is different from $\mathrm{T}$ cells triggered after immunization with immunodominant self-antigens such as CII or MOG (in CIA or EAE) and that Ltab-Ncr3 specifically regulates the former but not the later type of T-cell activation.

The nature of the priming of $\mathrm{T}$ cells in human autoimmune diseases is not known, and it is not possible to exclude any of the proposed scenarios that $\mathrm{T}$ cells are activated by adjuvants or by specific antigens. Infectious organisms contain molecular structures of which some have adjuvant effects that higher organisms have learned to recognize and trigger the innate and adaptive immune system. The various adjuvant oils used in this study belong to this category. In fact, similar adjuvant structures could also be contributed from the environment in the form of food or pollution, and occupational exposure to mineral oil has been associated with an increased risk of developing RA. ${ }^{34}$ This association was not related to the presence of shared epitope genotype,$^{34}$ and the possibility to study other genetic influence on arthritis induction by mineral oils in rats is therefore of unique value. Higher organisms are also exposed to a vast array of specific antigens in infectious organisms, in food, or in the environment that could mimic our self-antigens. We are, for example, exposed to potentially cross-reactive non-self-CII through food intake.

Over the past decades, various research groups have studied arthritis regulation in different congenic strains in rats. Most QTLs isolated in congenic strains regulated PIA (and OIA), as well as CIA. ${ }^{15,17,19,21,35,36}$ However, there were also a few congenic strains carrying QTLs, including Cia4, Cia5d, Cia6, and Cia10, which regulated only PIA and/or OIA but not CIA. ${ }^{17-19}$ These QTLs spanned $>20 \mathrm{Mb}$, and it is not clear whether within these QTLs there were multiple subloci. We previously showed, even for QTL smaller than $5 \mathrm{Mb}$, that there can still be arthritisregulatory subloci, and Ltab-Ncr3 was identified as one of the two arthritis-regulatory subloci in the MHC locus. ${ }^{8,9}$ To date, all other fine-mapped arthritis genes/loci, namely $N c f 1,{ }^{37} R T 1-B,{ }^{8,21}$ and APLEC,${ }^{16,38,39}$ have been shown to regulate both PIA (and OIA) and CIA. ${ }^{40}$ To our knowledge, the Ltab-Ncr3 haplotype is the first fine-mapped locus that regulates only oil adjuvant-induced arthritis models. Furthermore, unlike some arthritis-regulatory loci, such as Cia4, Cia5a, and Cia6, which have been reported to be sex influenced, ${ }^{41,42}$ we found that the Ltab-Ncr3 arthritisregulatory effect is independent of sex and age.

The Ltab-Ncr3 haplotype comprises five genes, namely Lta, Tnfa, Ltb, Lst 1 , and Ncr3, all of which are known to encode proteins with important immune roles ${ }^{43-49}$ and have been implicated in RA in humans. ${ }^{50-54} \mathrm{We}$ and others have previously shown significant coexpression of the Ltab-Ncr3 genes, suggesting how different genes may work together as a haplotype. ${ }^{9,51}$ In addition, we further showed that higher Ltb and Ncr3 expression, lower Lstl expression, and the expression of a shorter splice variant of Lst 1 in the Ltab-Ncr3 haplotype correlate with reduced arthritis severity in rats. ${ }^{9}$ It is therefore likely that concerted actions of these differentially expressed and alternatively spliced genes together contribute to the haplotype regulation of adjuvant-based autoimmunity demonstrated in this study. In addition to RA and multiple sclerosis discussed so far, LTAB-NCR3 has been associated with other inflammatory disorders in humans, including periodontitis, ${ }^{55}$ primary Sjögren's syndrome, ${ }^{56}$ psoriatic arthritis, ${ }^{57}$ Crohn disease, ${ }^{58}$ asthma, ${ }^{59}$ and myocardial 
infarction. ${ }^{60}$ This region was also associated with susceptibility to infections such as malaria ${ }^{61}$ hepatitis $\mathrm{C}$ infection, ${ }^{62}$ and pulmonary tuberculosis. ${ }^{63}$ The relevance of $L T A B-N C R 3$ association with adjuvant-driven immune response in these inflammatory diseases and infections remains to be established.

Other than animal immunization, adjuvants such as squalene and IFA are also incorporated into vaccines to enhance immunogenicity. However, it has been suggested that adjuvants may be associated with an increased risk of inflammatory adverse manifestations after administration. ${ }^{64}$ One of the main challenges in vaccination is to identify individuals who will develop adverse vaccine reactions, and it has been hypothesized that because susceptibility to oil adjuvant-induced arthritis is genetic in rodents, ${ }^{16,20}$ any humans with susceptible genetic features might also develop severe autoimmune response after immunization. In fact, a number of variants in the genes encoding HLA molecules, cytokines, cytokine receptors, Toll-like receptors, including the $L T A-T N F-L S T 1$ region, ${ }^{65}$ have been associated with responses to vaccines. ${ }^{66}$ Because we showed that $L t a b-N c r 3$ is associated to autoimmune response to adjuvants in rats, it can be of importance to investigate further if $L T A B-N C R 3$ is associated with any adverse response caused by adjuvants in the vaccination in humans.

\section{Conclusion}

We showed that a conserved 33-kb Ltab-Ncr3 haplotype in the telomeric end of MHC-III regulates T-cell-mediated adjuvant arthritis models but not autoimmunity triggered through immunization with specific tissue antigens. The Ltab-Ncr3 haplotype seems to control mechanisms of importance to explain early events in the triggering of an immune response, which can be of interest to not only autoimmunity but also other fields such as allergy and vaccination.

\section{Acknowledgments}

We thank Emma Mondoc for help in preparing and scoring histologic samples and Carlos Palestro, Kristina Palestro, Tomasz Klaczkowski, and Evelina Wernersson for taking care of the animals.

\section{Supplemental Data}

Supplemental material for this article can be found at http://dx.doi.org/10.1016/j.ajpath.2016.12.022.

\section{References}

1. Okada Y, Wu D, Trynka G, Raj T, Terao C, Ikari K, et al: Genetics of rheumatoid arthritis contributes to biology and drug discovery. Nature 2014, 506:376-381
2. Stastny P: Association of the B-cell alloantigen DRw4 with rheumatoid arthritis. N Engl J Med 1978, 298:869-871

3. Gregersen PK, Silver J, Winchester RJ: The shared epitope hypothesis. An approach to understanding the molecular genetics of susceptibility to rheumatoid arthritis. Arthritis Rheum 1987, 30: $1205-1213$

4. Raychaudhuri S, Sandor C, Stahl EA, Freudenberg J, Lee HS, Jia X, Alfredsson L, Padyukov L, Klareskog L, Worthington J, Siminovitch KA, Bae SC, Plenge RM, Gregersen PK, de Bakker PI: Five amino acids in three HLA proteins explain most of the association between MHC and seropositive rheumatoid arthritis. Nat Genet 2012, 44:291-296

5. Han B, Diogo D, Eyre S, Kallberg H, Zhernakova A, Bowes J, Padyukov L, Okada Y, González-Gay MA, Rantapää-Dahlqvist S, Martin J, Huizinga TW, Plenge RM, Worthington J, Gregersen PK, Klareskog L, de Bakker PI, Raychaudhuri S: Fine mapping seronegative and seropositive rheumatoid arthritis to shared and distinct HLA alleles by adjusting for the effects of heterogeneity. Am J Hum Genet 2014, 94:522-532

6. Harney SM, Vilariño-Güell C, Adamopoulos IE, Sims AM, Lawrence RW, Cardon LR, Newton JL, Meisel C, Pointon JJ, Darke C, Athanasou N, Wordsworth BP, Brown AM: Fine mapping of the MHC Class III region demonstrates association of AIF1 and rheumatoid arthritis. Rheumatology 2008, 47:1761-1767

7. Vignal C, Bansal AT, Balding DJ, Binks MH, Dickson MC, Montgomery DS, Wilson AG: Genetic association of the major histocompatibility complex with rheumatoid arthritis implicates two non-DRB1 loci. Arthritis Rheum 2009, 60:53-62

8. Haag S, Tuncel J, Thordardottir S, Mason DE, Yau AC, Dobritzsch D, Backlund J, Peters EC, Holmdahl R: Positional identification of RT1-B (HLA-DQ) as susceptibility locus for autoimmune arthritis. J Immunol 2015, 194:2539-2550

9. Yau AC, Tuncel J, Haag S, Norin U, Houtman M, Padyukov L, Holmdahl R: Conserved 33-kb haplotype in the MHC class III region regulates chronic arthritis. Proc Natl Acad Sci U S A 2016, 113: E3716-E3724

10. Holmdahl R, Goldschmidt TJ, Kleinau S, Kvick C, Jonsson R: Arthritis induced in rats with adjuvant oil is a genetically restricted, alpha beta T-cell dependent autoimmune disease. Immunology 1992, 76:197-202

11. Kleinau S, Klareskog L: Oil-induced arthritis in DA rats passive transfer by T cells but not with serum. J Autoimmun 1993, 6: $449-458$

12. Holmberg J, Tuncel J, Yamada H, Lu S, Olofsson P, Holmdahl R: Pristane, a non-antigenic adjuvant, induces MHC class II-restricted, arthritogenic T cells in the rat. J Immunol 2006, 176:1172-1179

13. Tuncel J, Haag S, Hoffmann MH, Yau AC, Hultqvist M, Olofsson P, Bäcklund J, Nandakumar KS, Weidner D, Fischer A, Leichsenring A, Lange F, Haase C, Lu S, Gulko PS, Steiner G, Holmdahl R: Animal models of rheumatoid arthritis (I): pristane-induced arthritis in the rat. PLoS One 2016, 11:e0155936

14. Kraetsch HG, Unger C, Wernhoff P, Schneider C, Kalden JR, Holmdahl R, Burkhardt H: Cartilage-specific autoimmunity in rheumatoid arthritis: characterization of a triple helical B cell epitope in the integrin-binding-domain of collagen type II. Eur J Immunol 2001, 31:1666-1673

15. Olofsson P, Lu S, Holmberg J, Song T, Wernhoff P, Pettersson U, Holmdahl R: A comparative genetic analysis between collageninduced arthritis and pristane-induced arthritis. Arthritis Rheum 2003, 48:2332-2342

16. Lorentzen JC, Glaser A, Jacobsson L, Galli J, Fakhrai-rad H, Klareskog L, Luthman H: Identification of rat susceptibility loci for adjuvant-oil-induced arthritis. Proc Natl Acad Sci U S A 1998, 95: 6383-6387

17. Remmers EF, Joe B, Griffiths MM, Dobbins DE, Dracheva SV, Hashiramoto A, Furuya T, Salstrom JL, Wang J, Gulko PS, Cannon GW, Wilder RL: Modulation of multiple experimental 
arthritis models by collagen-induced arthritis quantitative trait loci isolated in congenic rat lines: different effects of non-major histocompatibility complex quantitative trait loci in males and females. Arthritis Rheum 2002, 46:2225-2234

18. Brenner M, Meng HC, Yarlett NC, Griffiths MM, Remmers EF, Wilder RL, Gulko PS: The non-major histocompatibility complex quantitative trait locus Cia10 contains a major arthritis gene and regulates disease severity, pannus formation, and joint damage. Arthritis Rheum 2005, 52:322-332

19. Brenner M, Meng HC, Yarlett NC, Joe B, Griffiths MM, Remmers EF, Wilder RL, Gulko PS: The non-MHC quantitative trait locus Cia5 contains three major arthritis genes that differentially regulate disease severity, pannus formation, and joint damage in collagen- and pristane-induced arthritis. J Immunol 2005, 174: 7894-7903

20. Vingsbo-Lundberg C, Nordquist N, Olofsson P, Sundvall M, Saxne T, Pettersson U, Holmdahl R: Genetic control of arthritis onset, severity and chronicity in a model for rheumatoid arthritis in rats. Nat Genet 1998, 20:401-404

21. Tuncel J, Haag S, Carlsén S, Yau AC, Lu S, Burkhardt H, Holmdahl R: Class II major histocompatibility complex-associated response to type XI collagen regulates the development of chronic arthritis in rats. Arthritis Rheum 2012, 64:2537-2547

22. Bergsteinsdottir K, Yang HT, Pettersson U, Holmdahl R: Evidence for common autoimmune disease genes controlling onset, severity, and chronicity based on experimental models for multiple sclerosis and rheumatoid arthritis. J Immunol 2000, 164:1564-1568

23. Rintisch C, Holmdahl R: DA rats from two colonies differ genetically and in their arthritis susceptibility. Mamm Genome 2008, 19: $420-428$

24. Tuncel J, Haag S, Yau AC, Norin U, Baud A, Lönnblom E, Maratou K, Ytterberg AJ, Ekman D, Thordardottir S, Johannesson M, Gillett A; EURATRANS Consortium, Stridh P, Jagodic M, Olsson T, Fernández-Teruel A, Zubarev RA, Mott R, Aitman TJ, Flint J, Holmdahl R: Natural polymorphisms in Tap2 influence negative selection and CD4:CD8 lineage commitment in the rat. PLoS Genet 2014, 10:e1004151

25. Yau ACY, Piehl F, Olsson T, Holmdahl R: Effects of C2ta genetic polymorphisms on MHC class II expression and autoimmune diseases. Immunology 2017, 150:408-417

26. Carlson BC, Jansson AM, Larsson A, Bucht A, Lorentzen JC: The endogenous adjuvant squalene can induce a chronic T-cell-mediated arthritis in rats. Am J Pathol 2000, 156:2057-2065

27. Lorentzen JC: Identification of arthritogenic adjuvants of self and foreign origin. Scand J Immunol 1999, 49:45-50

28. Patsopoulos NA, Barcellos LF, Hintzen RQ, Schaefer C, van Duijn CM, Noble JA, Raj T; IMSGC; ANZgene, Gourraud PA, Stranger BE, Oksenberg J, Olsson T, Taylor BV, Sawcer S, Hafler DA, Carrington M, De Jager PL, de Bakker PI: Fine-mapping the genetic association of the major histocompatibility complex in multiple sclerosis: HLA and non-HLA effects. PLoS Genet 2013, 9:e1003926

29. Tuncel J, Haag S, Holmdahl R: MHC class II alleles associated with Th1 rather than Th17 type immunity drive the onset of early arthritis in a rat model of rheumatoid arthritis. Eur J Immunol 2017, 47: $563-574$

30. Holmdahl R, Kvick C: Vaccination and genetic experiments demonstrate that adjuvant-oil-induced arthritis and homologous type II collagen-induced arthritis in the same rat strain are different diseases. Clin Exp Immunol 1992, 88:96-100

31. Lorentzen JC, Erlandsson H, Mussener A, Mattsson L, Kleinau S, Nyman U, Klareskog L: Specific and long-lasting protection from collagen-induced arthritis and oil-induced arthritis in DA rats by administration of immunogens. Scand J Immunol 1995, 42:82-89

32. Goldschmidt TJ, Holmdahl R: Anti-T cell receptor antibody treatment of rats with established autologous collagen-induced arthritis: suppression of arthritis without reduction of anti-type II collagen autoantibody levels. Eur J Immunol 1991, 21:1327-1330
33. Holmdahl R, Lorentzen JC, Lu S, Olofsson P, Wester L, Holmberg J, Pettersson U: Arthritis induced in rats with nonimmunogenic adjuvants as models for rheumatoid arthritis. Immunol Rev 2001, 184:184-202

34. Sverdrup B, Källberg H, Bengtsson C, Lundberg I, Padyukov L, Alfredsson L, Klareskog L; Epidemiological Investigation of Rheumatoid Arthritis Study Group: Association between occupational exposure to mineral oil and rheumatoid arthritis: results from the Swedish EIRA case-control study. Arthritis Res Ther 2005, 7: R1296-R1303

35. Brenner M, Laragione T, Shah A, Mello A, Remmers EF, Wilder RL, Gulko PS: Identification of two new arthritis severity loci that regulate levels of autoantibodies, interleukin-1[beta], and joint damage in pristane- and collagen-induced arthritis. Arthritis Rheum 2012, 64: $1369-1378$

36. Brenner M, Laragione T, Mello A, Gulko PS: Cia25 on rat chromosome 12 regulates severity of autoimmune arthritis induced with pristane and with collagen. Ann Rheum Dis 2007, 66:952-957

37. Olofsson P, Holmberg J, Tordsson J, Lu S, Akerström B, Holmdahl R: Positional identification of $\mathrm{Ncf1}$ as a gene that regulates arthritis severity in rats. Nat Genet 2003, 33:25-32

38. Rintisch C, Kelkka T, Norin U, Lorentzen JC, Olofsson P, Holmdahl R: Finemapping of the arthritis QTL Pia7 reveals colocalization with Oia2 and the APLEC locus. Genes Immun 2010, $11: 239-245$

39. Lorentzen JC, Flornes L, Eklöw C, Båckdahl L, Ribbhammar U, Guo JP, Smolnikova M, Dissen E, Seddighzadeh M, Brookes AJ, Alfredsson L, Klareskog L, Padyukov L, Fossum S: Association of arthritis with a gene complex encoding C-type lectin-like receptors. Arthritis Rheum 2007, 56:2620-2632

40. Yau AC, Holmdahl R: Rheumatoid arthritis: identifying and characterising polymorphisms using rat models. Dis Model Mech 2016, 9 : $1111-1123$

41. Joe B, Remmers EF, Dobbins DE, Salstrom JL, Furuya T, Dracheva S, Gulko PS, Cannon GW, Griffiths MM, Wilder RL: Genetic dissection of collagen-induced arthritis in chromosome 10 quantitative trait locus speed congenic rats: evidence for more than one regulatory locus and sex influences. Immunogenetics 2000, 51:930-944

42. Joe B, Cannon GW, Griffiths MM, Dobbins DE, Gulko PS, Wilder RL, Remmers EF: Evaluation of quantitative trait loci regulating severity of mycobacterial adjuvant-induced arthritis in monocongenic and polycongenic rats: identification of a new regulatory locus on rat chromosome 10 and evidence of overlap with rheumatoid arthritis susceptibility loci. Arthritis Rheum 2002, 46:1075-1085

43. Draber P, Stepanek O, Hrdinka M, Drobek A, Chmatal L, Mala L, Ormsby T, Angelisova P, Horejsi V, Brdicka T: LST1/A is a myeloid leukocyte-specific transmembrane adaptor protein recruiting protein tyrosine phosphatases SHP-1 and SHP-2 to the plasma membrane. J Biol Chem 2012, 287:22812-22821

44. Rollinger-Holzinger I, Eibl B, Pauly M, Griesser U, Hentges F, Auer B, Pall G, Schratzberger P, Niederwieser D, Weiss EH, Zwierzina H: LST1: a gene with extensive alternative splicing and immunomodulatory function. J Immunol 2000, 164:3169-3176

45. Körner H, Cook M, Riminton DS, Lemckert FA, Hoek RM, Ledermann B, Köntgen F, Fazekas de St Groth B, Sedgwick JD: Distinct roles for lymphotoxin-alpha and tumor necrosis factor in organogenesis and spatial organization of lymphoid tissue. Eur J Immunol 1997, 27:2600-2609

46. De Togni P, Goellner J, Ruddle NH, Streeter PR, Fick A, Mariathasan S, Smith SC, Carlson R, Shornick LP, Strauss-Schoenberger J, Russell JH, Karr R, Chaplin DD: Abnormal development of peripheral lymphoid organs in mice deficient in lymphotoxin. Science 1994, 264:703-707

47. Brandt CS, Baratin M, Yi EC, Kennedy J, Gao Z, Fox B, Haldeman B, Ostrander CD, Kaifu T, Chabannon C, Moretta A, West R, Xu W, Vivier E, Levin SD: The B7 family member B7-H6 is a tumor cell ligand for the activating natural killer cell receptor NKp30 in humans. J Exp Med 2009, 206:1495-1503 
48. Hsieh CL, Nagasaki K, Martinez OM, Krams SM: NKp30 is a functional activation receptor on a subset of rat natural killer cells. Eur J Immunol 2006, 36:2170-2180

49. Browning JL, Ngam-ek A, Lawton P, DeMarinis J, Tizard R, Chow EP, Hession C, O'Brine-Greco B, Foley SF, Ware CF: Lymphotoxin [beta], a novel member of the TNF family that forms a heteromeric complex with lymphotoxin on the cell surface. Cell 1993, 72:847-856

50. O'Rourke KP, O'Donoghue G, Adams C, Mulcahy H, Molloy C, Silke C, Molloy M, Shanahan F, O'Gara F: High levels of Lymphotoxin-Beta (LT-Beta) gene expression in rheumatoid arthritis synovium: clinical and cytokine correlations. Rheumatol Int 2008, 28 : 979-986

51. Mulcahy H, O'Rourke KP, Adams C, Molloy MG, O'Gara F: LST1 and NCR3 expression in autoimmune inflammation and in response to IFN-[gamma], LPS and microbial infection. Immunogenetics 2006, $57: 893-903$

52. Toonen EJ, Barrera P, Fransen J, de Brouwer AP, Eijsbouts AM, Miossec P, Marotte H, Scheffer H, van Riel PL, Franke B, Coenen MJ: Meta-analysis identified the TNFA -308G $>$ A promoter polymorphism as a risk factor for disease severity in patients with rheumatoid arthritis. Arthritis Res Ther 2012, 14:R264

53. Bienkowska J, Allaire N, Thai A, Goyal J, Plavina T, Nirula A, Weaver M, Newman C, Petri M, Beckman E, Browning JL: Lymphotoxin-LIGHT pathway regulates the interferon signature in rheumatoid arthritis. PLoS One 2014, 9:e112545

54. Santos MJ, Fernandes D, Caetano-Lopes J, Perpetuo IP, Vidal B, Canhao H, Fonesca JE: Lymphotoxin-[alpha] 252 A>G polymorphism: a link between disease susceptibility and dyslipidemia in rheumatoid arthritis? J Rheumatol 2011, 38: $1244-1249$

55. Kallio KA, Marchesani M, Vlachopoulou E, Mäntylä P, Paju S, Buhlin K, Suominen AL, Contreras J, Knuuttila M, Hernandez M, Huumonen S, Nieminen MS, Perola M, Sinisalo J, Lokki ML, Pussinen PJ: Genetic variation on the BAT1NFKBIL1-LTA region of major histocompatibility complex class III associates with periodontitis. Infect Immun 2014, 82: 1939-1948

56. Bolstad AI, Le Hellard S, Kristjansdottir G, Vasaitis L, Kvarnstrom M, Sjowall C, Johnsen SJ, Eriksson P, Omdal R, Brun JG, Wahren-Herlenius M, Theander E, Syvanen AC, Ronnblom L,
Nordmark G, Jonsson R: Association between genetic variants in the tumour necrosis factor/lymphotoxin [alpha]/lymphotoxin [beta] locus and primary Sjogren's syndrome in Scandinavian samples. Ann Rheum Dis 2012, 71:981-988

57. Balding J, Kane D, Livingstone W, Mynett-Johnson L, Bresnihan B, Smith O, FitzGerald O: Cytokine gene polymorphisms: association with psoriatic arthritis susceptibility and severity. Arthritis Rheum 2003, 48:1408-1413

58. Franke A, McGovern DP, Barrett JC, Wang K, Radford-Smith GL, Ahmad T, et al: Genome-wide meta-analysis increases to 71 the number of confirmed Crohn's disease susceptibility loci. Nat Genet 2010, 42:1118-1125

59. Shin HD, Park BL, Kim LH, Jung JH, Wang HJ, Kim YJ, Park HS, Hong SJ, Choi BW, Kim DJ, Park CS: Association of tumor necrosis factor polymorphisms with asthma and serum total IgE. Hum Mol Genet 2004, 13:397-403

60. Li N, Liu R, Zhai H, Li L, Yin Y, Zhang J, Xia Y: Polymorphisms of the LTA gene may contribute to the risk of myocardial infarction: a meta-analysis. PLoS One 2014, 9:e92272

61. Gichohi-Wainaina WN, Melse-Boonstra A, Feskens EJ, Demir AY, Veenemans J, Verhoef H: Tumour necrosis factor allele variants and their association with the occurrence and severity of malaria in African children: a longitudinal study. Malar J 2015, 14:249

62. Mantovani S, Mele D, Oliviero B, Barbarini G, Varchetta S, Mondelli MU: NKp30 isoforms in patients with chronic hepatitis C virus infection. Immunology 2015, 146:234-242

63. Yi YX, Han JB, Zhao L, Fang Y, Zhang YF, Zhou GY: Tumor necrosis factor alpha gene polymorphism contributes to pulmonary tuberculosis susceptibility: evidence from a meta-analysis. Int J Clin Exp Med 2015, 8:20690-20700

64. Cerpa-Cruz S, Paredes-Casillas P, Landeros Navarro E, BernardMedina AG, Martínez-Bonilla G, Gutiérrez-Ureña S: Adverse events following immunization with vaccines containing adjuvants. Immunol Res 2013, 56:299-303

65. Ovsyannikova IG, Vierkant RA, Pankratz VS, Jacobson RM, Poland GA, Extended LTA: TNF, LST1 and HLA gene haplotypes and their association with rubella vaccine-induced immunity. PLoS One 2010, 5:e11806

66. Newport MJ: The genetic regulation of infant immune responses to vaccination. Front Immunol 2015, 6:18 